\title{
Congenital Transmission of Trypanosoma cruzi in Argentina, Honduras, and Mexico: An Observational Prospective Study
}

\author{
Pierre Buekens, ${ }^{1 \star}$ María Luisa Cafferata, ${ }^{2}$ Jackeline Alger, ${ }^{3}$ Fernando Althabe, ${ }^{4}$ José M. Belizán, ${ }^{4}$ Norma Bustamante,${ }^{5}$ \\ Yves Carlier, ${ }^{1,6}$ Alvaro Ciganda, ${ }^{2}$ Jaime H. del Cid, ${ }^{7}$ Eric Dumonteil, ${ }^{1}$ Rubí Gamboa-León, ${ }^{8}$ Jorge A. García, ${ }^{3}$ Luz Gibbons, ${ }^{4}$ \\ Olga Graiff, ${ }^{9}$ Jesús Gurubel Maldonado, ${ }^{10}$ Claudia Herrera, ${ }^{1}$ Elizabeth Howard, ${ }^{1}$ Laura Susana Lara, ${ }^{9}$ Benjamín López, ${ }^{5}$ \\ María Luisa Matute, ${ }^{11}$ María Jesús Ramírez-Sierra, ${ }^{10}$ María Cecilia Robles, ${ }^{9}$ Sergio Sosa-Estani, ${ }^{4,12}$ Carine Truyens, ${ }^{6}$ \\ Christian Valladares, ${ }^{11}$ Dawn M. Wesson, ${ }^{1}$ and Concepción Zúniga ${ }^{3}$; for the Congenital Chagas Working Group† \\ ${ }^{1}$ Tulane University School of Public Health and Tropical Medicine, New Orleans, Louisiana; ${ }^{2}$ Unidad de Investigación Clínica y \\ Epidemiológica Montevideo (UNICEM), Montevideo, Uruguay; ${ }^{3}$ Hospital Escuela Universitario, Facultad de Ciencias Médicas, UNAH, \\ Tegucigalpa, Honduras; ${ }^{4}$ Instituto de Efectividad Clínica y Sanitaria (IECS), Buenos Aires, Argentina; ${ }^{5}$ Región Departamental de Salud, Santa \\ Bárbara, Honduras; ${ }^{6}$ Laboratory of Parasitology, Faculty of Medicine, Université Libre de Bruxelles (ULB), Brussels, Belgium; ${ }^{7}$ Centro de Salud \\ Vicente Mejía Colindres, Intibucá, Honduras; ${ }^{8}$ Universidad Autónoma de San Luis Potosí, Tamazunchale, México; ${ }^{9}$ Instituto de Maternidad y \\ Ginecología Nuestra Señora de las Mercedes, San Miguel de Tucumán, Argentina; ${ }^{10}$ Centro de Investigaciones Regionales \\ "Dr. Hideyo Noguchi," Universidad Autónoma de Yucatán, Mérida, México; ${ }^{11}$ Laboratorio Nacional de Vigilancia de la Salud, \\ Secretaría de Salud de Honduras, Tegucigalpa, Honduras; ${ }^{12}$ Instituto Nacional de Parasitología "Dr. Mario Fatala Chaben," CONICET, \\ ANLIS, Buenos Aires, Argentina
}

\begin{abstract}
Compared with South America, there is a lack of epidemiologic studies about the risk of congenital transmission of Trypanosoma cruzi in Central America and Mexico. It has been suggested that $T$. cruzi genotypes might differ by region and that congenital transmission might vary according to the parasite's genotype. Our objective was to compare $T$. cruzi congenital transmission rates in three countries. We performed an observational prospective study in 2011-2014 enrolling women at delivery in one hospital in Argentina, two hospitals in Honduras, and two hospitals in Mexico. Congenital T. cruzi infection was defined as the presence of one or more of the following criteria: presence of parasites in cord blood (direct parasitological microscopic examination) with positive polymerase chain reaction (PCR) in cord blood, presence of parasites in infant's blood at 4-8 weeks (direct parasitological microscopic examination), and persistence of $T$. cruzi-specific antibodies at 10 months, as measured by at least two tests. Among 28,145 enrolled women, 347 had at least one antibody rapid test positive in cord blood and a positive enzyme-linked immunosorbent assay in maternal blood. PCR in maternal blood was positive in $73.2 \%$ of the cases, and genotyping identified a majority of non-Tcl in the three countries. We found no $(0.0 \% ; 95 \%$ confidence interval $[\mathrm{Cl}]: 0.0,2.0)$ confirmed congenital case in Honduras. Congenital transmission was 6.6\% (95\% Cl: 3.1, 12.2) in Argentina and 6.3\% (95\% Cl: 0.8, 20.8$)$ in Mexico. Trypanosoma cruzi non-Tcl predominated and risks of congenital transmission were similar in Argentina and Mexico.
\end{abstract}

\section{INTRODUCTION}

Chagas disease, or American trypanosomiasis, is caused by the protozoan parasite Trypanosoma cruzi. It is a major cause of cardiac disease in the Americas. An estimated six million persons are currently infected, including one million women of reproductive age. ${ }^{1}$ Mothers can transmit $T$. cruzi to their infants during pregnancy, but infected newborns can be effectively treated if detected early. ${ }^{2,3} \mathrm{~A}$ meta-analysis of available data showed a $5.0 \%$ congenital transmission rate in endemic countries, based mostly on studies from South America. ${ }^{4}$ Before the current study, there were only limited data about transmission rates in Mexico and Central America. A single confirmed case of congenital transmission has been previously reported in Mexico. ${ }^{5}$ Other Mexican studies relied mostly on polymerase chain reaction (PCR) on cord blood to diagnose congenital transmission of $T$. cruzi ${ }^{6-8}$ A recent study identified one case of congenital Chagas disease among 32 infected mothers in El Salvador. ${ }^{9}$

It has been suggested that the congenital transmission rate might vary according to the parasite's genotype, but available data are inconclusive. ${ }^{10-13}$ Trypanosoma cruzi genotypes have been grouped into discrete typing units (DTUs), with Tcl

*Address correspondence to Pierre Buekens, Tulane University School of Public Health and Tropical Medicine, 1440 Canal Street, Suite 2400, New Orleans, LA 70112. E-mail: pbuekens@tulane.edu † The members of the Congenital Chagas Working Group are listed in the Appendix. being assumed to be more frequent in Mexico and Central America and non-Tcl (Tcll-VI) being dominant in the Southern Cone region of South America. ${ }^{14,15}$ However, recent studies suggest that $\mathrm{Tcl}$ might not be predominant in all regions of Mexico. $^{16}$

A better knowledge of the risk of congenital transmission is a prerequisite to the establishment of universal screening programs for $T$. cruzi infection among pregnant women and infants. ${ }^{17,18}$ Institutional delivery is almost universal in Latin America, allowing for hospital recruitment of study populations. ${ }^{19}$ The objective of this study was to compare T. cruzi congenital transmission rates in Argentina, Honduras, and Mexico, using a common methodology.

\section{MATERIALS AND METHODS}

The protocol was previously published, ${ }^{20}$ and the study was registered in ClinicalTrials.gov: Identifier NCT01787968.

Study design and participants. This was an observational prospective study conducted in one hospital in Argentina (Instituto de Maternidad y Ginecología Nuestra Señora de las Mercedes, Tucumán), two hospitals in Honduras (Hospital Enrique Aguilar Cerrato, La Esperanza, Intibucá and Hospital Santa Bárbara Integrado, Santa Bárbara), and two hospitals in Mexico (Hospital Materno Infantil, Mérida, Yucatán and Hospital General de Valladolid, Valladolid, Yucatán).

During 2011-2013, we enrolled women at delivery and collected umbilical cord blood to measure antibodies of 
maternal origin. We collected blood with needle and syringe from the placental side after clamping and sectioning the cord and after cleaning it with a sterile gauze pad. We obtained written informed consent immediately after delivery and before testing the cord blood. The eligible women were 18 years old or more, had a live birth, and resided inside of the follow-up areas (Province of Tucumán, Argentina; Departments of Intibucá and Santa Bárbara, Honduras; States of Campeche, Quintana Roo, and Yucatán, Mexico). If one of the cord blood rapid antibody tests was positive, maternal infection was confirmed by serology in maternal blood collected immediately after delivery. Seropositive mothers had at least one positive antibody rapid test on cord blood and a positive enzyme-linked immunosorbent assay (ELISA) on maternal blood. Those newborns with at least one positive antibody rapid test for $T$. cruzi in cord blood were tested with a direct parasitological examination on cord blood and were followed up at their homes at 4-8 weeks and 10 months postpartum by a dedicated and trained team in each country. At the 4-8 weeks postpartum home visit, we repeated the parasitological examination on those infants with a negative examination on cord blood. At the 10-month postpartum visit, we collected venous blood for serology on all followed up infants. During the visits, infants' siblings who assented or consented to participate were tested for $T$. cruzi infection. Infected newborns and siblings were referred for treatment according to local standards, which included a course of 30-60 days of benznidazole or nifurtimox.

Laboratory procedures. We performed two antibody rapid tests in cord blood and at 10 months: Stat-Pak (Chembio, Medford, NY) and Trypanosoma Detect (T-Detect) (InBios, Seattle, WA). We also used Stat-Pak among siblings. We performed serological confirmation by ELISA (Chagatest ELISA recombinant, version 3.0; Wiener, Rosario, Argentina) in cord and maternal blood and at 10 months of age. A second confirmatory ELISA (Chagas Kit; Hemagen, Columbia, MD) was performed for 10 months samples that were positive for one test or more. We did direct microscopic examination of blood buffy coat in six centrifuged microhematocrit heparinized tubes per sample, after training all laboratory technicians and within a maximum of 6 hours after collecting the samples. ${ }^{21}$ The samples to be stored for further molecular testing were immediately mixed with the same volume of guanidine$\mathrm{HCl} 6 \mathrm{M}$, ethylenediaminetetraacetic acid (EDTA) 0.1 M (pH 8). We performed PCR followed by detection of the amplicons by gel electrophoresis on maternal and cord blood using two specific primer sets: Tcz1-Tcz2 and 121-122. ${ }^{22}$ The amount of blood collected at 4-8 weeks was not sufficient for PCR. A positive PCR was positive for at least one of the primer sets. Maternal parasitic load was determined by real-time quantitative PCR (qPCR) with Tcz1-Tcz2 primers. ${ }^{23}$ A multiplex PCR amplifying the miniexon genes intermediate region allowed us to discriminate the $T$. cruzi DTUs present in maternal blood samples as $\mathrm{Tcl}$ and non-Tcl. ${ }^{11} \mathrm{~A}$ limited number of amplicons were sequenced at Beckman Coulter Genomics (Takeley, United Kingdom) using the Sanger method for confirmation of genotyping. All molecular analyses, except sequencing, were performed in Brussels, Belgium, and were conducted under strict quality control. The molecular methods that were not detailed in the published protocol ${ }^{20}$ are included in the Supplemental Material (appendix).
Outcomes. The primary outcome was the congenital $T$. cruzi infection, defined as the presence of one or more of the following criteria: presence of parasites in cord blood (direct parasitological microscopic examination) with positive PCR in cord blood; presence of parasites in infant's blood at 48 weeks (direct parasitological microscopic examination); and persistence of $T$. cruzi-specific antibodies at 10 months, as measured by at least two tests. The primary outcome analyses were performed among newborns with at least one positive antibody rapid test on cord blood and a positive Wiener ELISA on maternal blood.

Statistical analysis. We described the maternal and newborn characteristics and the results of serological tests, PCR, qPCR, and sequencing. Sequences were analyzed by BLAST, ${ }^{24}$ edited manually and aligned with $T$. cruzi reference sequences for DTU assignment using MEGA version 5.2. ${ }^{25}$ For the primary outcome, we reported the proportions with the exact binomial confidence interval. $x^{2}$ and Fisher's exact tests were used to compare proportions. We used the Bonferroni correction to compare the proportions between the three countries. We used Kruskall-Wallis tests to compare median equivalent parasites per millilitre $(\mathrm{eP} / \mathrm{mL})$. Statistical significance was defined as $P<0.05$. Tests are two-sided. We used SAS (Cary, $\mathrm{NC)}$ version 9.3 for data analysis.

Ethics. All participating women and siblings provided informed consent or assent to participate in the study. The study was approved by the Tulane University Institutional Review Board, and the Ethics Committees of the Centro de Educación Médica e Investigaciones Clínicas “Norberto Quirno” (CEMIC), Argentina, the Facultad de Ciencias Médicas, Universidad Nacional Autónoma de Honduras, and the Universidad Autónoma de Yucatán, Mexico.

\section{RESULTS}

The study took place between April 2011 and December 2013. Figure 1 shows that $46,421(78.7 \%)$ of the 59,000 women who delivered during the study period were screened for eligibility and that 28,145 were enrolled (9,390 in Argentina, 6,595 in Honduras, and 12,160 in Mexico). Table 1 shows that maternal and neonatal characteristics differed between countries $(P<0.01)$. Enrolled women in Mexico were less likely to be 35 years or older, more likely to be primiparae, and more likely to have a high school or higher education. Honduras had the lowest cesarean section rate. The low birthweight $(<2,500 \mathrm{~g})$ rate and the rate of preterm $(<37$ weeks) births were low in Mexico.

We identified 495 (1.8\%) women with at least one antibody rapid test positive in the cord blood of at least one of their 503 (1.8\%) newborns, and we followed-up more than $95 \%$ of them (Figure 1). Mothers of newborns with at least one antibody rapid test positive in cord blood also had a positive Wiener ELISA in $87.0 \%(134 / 154)$ of the cases in Argentina and in $78.7 \%(181 / 230)$ of the cases in Honduras, but in only $29.4 \%$ $(32 / 109)$ of the cases in Mexico $(P<0.01)$ (Table 2$)$. The primary outcome analyses were performed among the 350 newborns of the 347 seropositive mothers.

Table 2 shows that PCR in maternal blood was positive in more than $70 \%$ of the cases in Argentina (105/134) and Honduras (132/181), but in only $53.1 \%(17 / 32)$ of the cases in Mexico $(P=0.015)$, and that genotyping identified a predominance of non-Tcl in the three countries. We obtained 


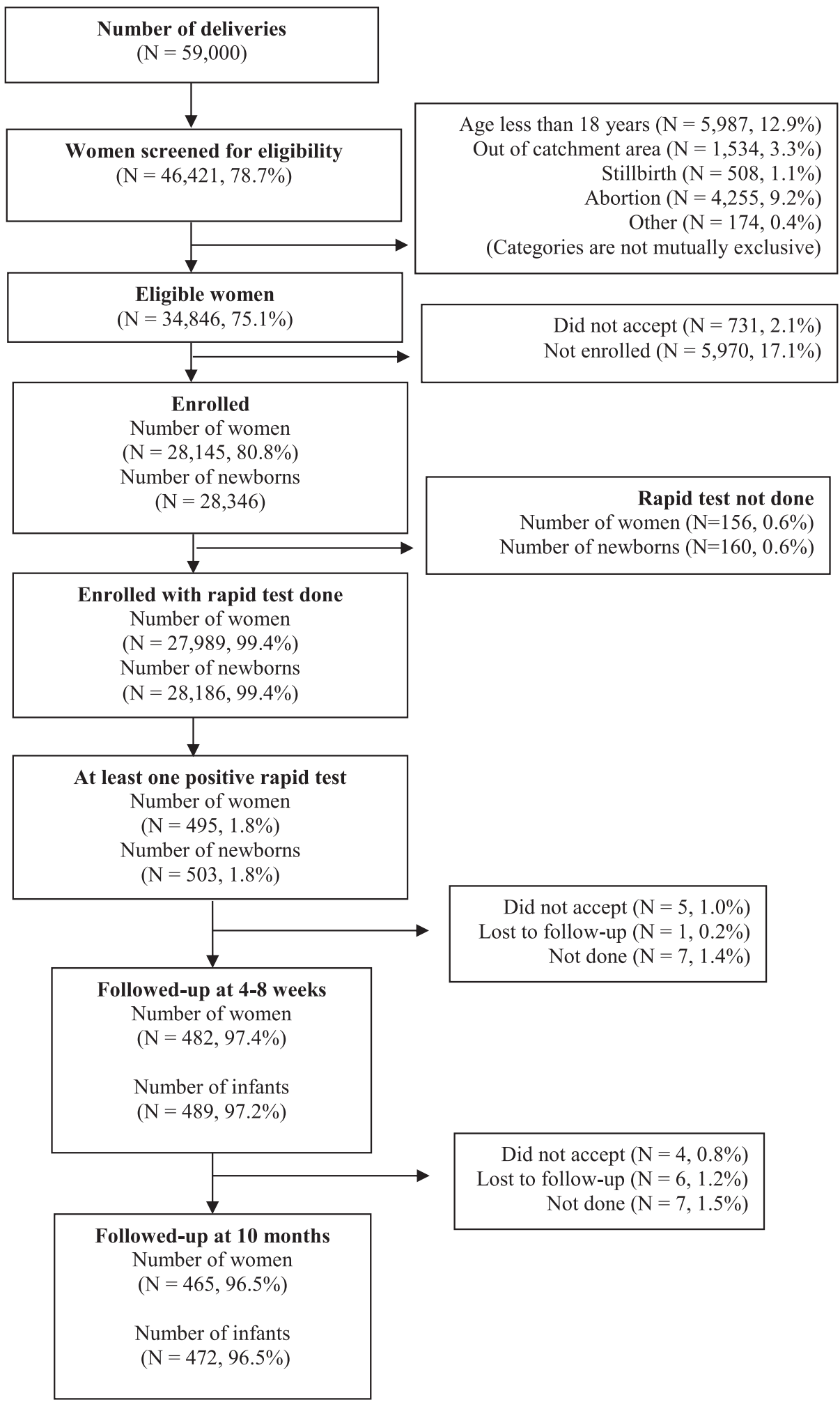

FIGURE 1. Recruitment flow chart.

sequencing of the PCR products in 31 of 107 genotyped maternal samples (13 from Argentina, 17 from Honduras, and one from Mexico). Sequence analyses confirmed PCR genotyping in all cases of mothers that were infected with $\mathrm{Tcl}$ or non-Tcl only, whereas in the case of maternal mixed infection, we obtained the sequences for both Tcl and non-Tcl in two mothers and the sequence for one genotype for others. In total, we detected by sequencing: Tcl only in $16.1 \%(5 / 31)$, non-Tcl in $77.4 \%$ (24/31), and mixed infection Tcl and non-Tcl in $6.5 \%(2 / 31)$ of maternal samples. Parasitic load measured by qPCR was not statistically significantly different in the three countries $(P=0.089)$ (Figure 2$)$, with a median of $3.4 \mathrm{eP} / \mathrm{mL}$ in 
TABLE 1

Maternal and neonatal characteristics by country

\begin{tabular}{|c|c|c|c|c|c|c|}
\hline & \multicolumn{2}{|c|}{$\begin{array}{c}\text { Argentina } \\
\text { (number of women }=9,390 \text { ) } \\
\text { (number of infants }=9,497 \text { ) }\end{array}$} & \multicolumn{2}{|c|}{$\begin{array}{c}\text { Honduras } \\
\text { (number of women }=6,595 \text { ) } \\
\text { (number of infants }=6,654 \text { ) }\end{array}$} & \multicolumn{2}{|c|}{$\begin{array}{c}\text { Mexico } \\
\text { (number of women }=12,160 \text { ) } \\
\text { (number of infants }=12,195 \text { ) }\end{array}$} \\
\hline & $n / N$ & $\%$ & $n / N$ & $\%$ & $n / N$ & $\%$ \\
\hline \multicolumn{7}{|l|}{ Maternal age (years) ${ }^{\star}$} \\
\hline $18-19$ & $1,291 / 9,390$ & 13.8 & 969/6,595 & 14.7 & $1,914 / 12,160$ & 15.7 \\
\hline $20-34$ & $7,080 / 9,390$ & 75.4 & $4,883 / 6,595$ & 74.0 & $9,322 / 12,160$ & 76.7 \\
\hline$\geq 35$ & $1,019 / 9,390$ & 10.9 & $743 / 6,595$ & 11.3 & $924 / 12,160$ & 7.6 \\
\hline \multicolumn{7}{|l|}{ Previous deliveries* } \\
\hline 0 & $4,536 / 9,384$ & 48.3 & 2,724/6,595 & 41.3 & $6,677 / 12,137$ & 55.0 \\
\hline$\geq 1$ & $4,848 / 9,384$ & 51.7 & $3,871 / 6,595$ & 58.7 & $5,460 / 12,137$ & 45.0 \\
\hline \multicolumn{7}{|l|}{ Education* } \\
\hline Elementary school or lower & $5,766 / 9,122$ & 63.2 & $4,820 / 6,593$ & 73.1 & $3,932 / 12,085$ & 32.5 \\
\hline High school or higher & $3,356 / 9,122$ & 36.8 & $1,773 / 6,593$ & 26.9 & $8,153 / 12,085$ & 67.5 \\
\hline \multicolumn{7}{|l|}{ Mode of delivery } \\
\hline Vaginal & $5,697 / 9,388$ & 60.7 & $5,217 / 6,595$ & 79.1 & $6,501 / 12,150$ & 53.5 \\
\hline Cesarean section & $3,691 / 9,388$ & 39.3 & $1,378 / 6,595$ & 20.9 & $5,649 / 12,150$ & 46.5 \\
\hline \multicolumn{7}{|l|}{ Birthweight $(g)^{\star}$} \\
\hline$<2,500$ & $761 / 9,491$ & 8.0 & $572 / 6,654$ & 8.6 & $697 / 12,194$ & 5.7 \\
\hline$\geq 2,500$ & $8,730 / 9,491$ & 92.0 & $6,082 / 6,654$ & 91.4 & $11,497 / 12,194$ & 64.3 \\
\hline \multicolumn{7}{|l|}{ Gestational age (weeks) ${ }^{\star}$} \\
\hline$<37$ & $1,126 / 9,452$ & 11.9 & $342 / 6,610$ & 5.2 & $580 / 12,156$ & 4.8 \\
\hline$\geq 37$ & $8,326 / 9,452$ & 88.1 & $6,268 / 6,610$ & 94.8 & $11,576 / 12,156$ & 95.2 \\
\hline
\end{tabular}

Argentina, $3.3 \mathrm{eP} / \mathrm{mL}$ in Honduras, and $2.5 \mathrm{eP} / \mathrm{mL}$ in Mexico. PCR tests on cord blood of seropositive mothers were positive in 45.6\% (62/136) of the cases in Argentina, 69.8\% (127/182) in Honduras, and $24.1 \%(7 / 29)$ in Mexico.

Congenital transmission as defined previously was $6.6 \%$ $(9 / 136)$ in Argentina, including two cases identified by parasitological examination (filmed) and PCR at birth, one case by parasitological examination (filmed) at 4-8 weeks, and six cases with at least two positive serological tests at 10 months (Table 3, Supplemental Table 1). A similar transmission rate of $6.3 \%(2 / 32)$ was found in Mexico, with one case identified by parasitological examination (not filmed) and PCR at birth and another one identified at 10 months. We found no confirmed case in Honduras, which had a statistically significant lower transmission rate than the one observed in Argentina $(P=$ $0.001)$ but not in Mexico $(P=0.065)$. All Argentine cases received treatment, and the Mexican cases were referred but not treated. The Mexican case identified at birth by positive parasitological examination and positive PCR had negative serological tests at 10 months (neither positive antibody rapid test nor positive ELISA), despite the fact that it was not treated.

PCR on maternal blood was positive in eight of the nine Argentine congenital cases and in both Mexican cases. Genotyping on maternal blood was successfully performed in four Argentine cases and in one Mexican case, and all cases in Argentina and the one in Mexico showed non-Tcl DTUs. The genotyping was confirmed by sequencing in three Argentine cases. There was a nonstatistically significant trend for higher

TABLE 2

Maternal Trypanosoma cruzi serology at delivery and polymerase chain reaction (PCR) and genotyping in maternal blood from seropositive mothers (with at least one positive antibody rapid test in cord blood and a positive enzyme-linked immunosorbent assay [ELISA] Wiener in maternal blood) by country

\begin{tabular}{|c|c|c|c|c|c|c|}
\hline & \multicolumn{2}{|c|}{ Argentina $(N=9,390)$} & \multicolumn{2}{|c|}{ Honduras $(N=6,595)$} & \multicolumn{2}{|c|}{ Mexico $(N=12,160)$} \\
\hline & $n / N$ & $\%$ & $n / N$ & $\%$ & $n / N$ & $\%$ \\
\hline \multicolumn{7}{|l|}{ Rapid tests in cord blood } \\
\hline Both rapid tests positive & $129 / 9,339$ & 1.4 & $183 / 6,583$ & 2.8 & $38 / 12,067$ & 0.3 \\
\hline Only Stat-Pak positive & 22/9,339 & 0.2 & $39 / 6,583$ & 0.6 & $36 / 12,067$ & 0.3 \\
\hline Only T-Detect positive & $4 / 9,339$ & 0.1 & $9 / 6,583$ & 0.1 & $35 / 12,067$ & 0.3 \\
\hline \multicolumn{7}{|c|}{ ELISA Wiener in maternal blood ${ }^{*} \dagger$} \\
\hline Positive & $134 / 154$ & 87.0 & $181 / 230$ & 78.7 & $32 / 109$ & 29.4 \\
\hline Negative & $20 / 154$ & 13.0 & $49 / 230$ & 21.3 & $75 / 109$ & 68.8 \\
\hline Inconclusive & $0 / 154$ & 0.0 & $0 / 230$ & 0.0 & $2 / 109$ & 1.8 \\
\hline \multicolumn{7}{|l|}{ PCR in maternal blood $\ddagger \S$} \\
\hline Positive & $105 / 134$ & 78.4 & $132 / 181$ & 72.9 & $17 / 32$ & 53.1 \\
\hline Negative & $29 / 134$ & 21.6 & $49 / 181$ & 27.1 & $15 / 32$ & 46.9 \\
\hline \multicolumn{7}{|c|}{ Genotyping in maternal blood $\ddagger \|$} \\
\hline Only non-Tcl & $23 / 105$ & 21.9 & $54 / 132$ & 40.9 & $6 / 17$ & 35.3 \\
\hline Only Tcl & $6 / 105$ & 5.7 & $1 / 132$ & 0.8 & $1 / 17$ & 5.9 \\
\hline Both Tcl and non-Tcl & $6 / 105$ & 5.7 & 10/132 & 7.6 & $0 / 17$ & 0.0 \\
\hline Undetermined & $70 / 105$ & 66.7 & $67 / 132$ & 50.8 & $10 / 17$ & 58.8 \\
\hline
\end{tabular}

$\dagger P<0.01$

$\ddagger$ Among women with at least one positive rapid test in cord blood and a positive ELISA Wiener in maternal blood.

$\S P=0.015$.

$\| P=0.009$. 


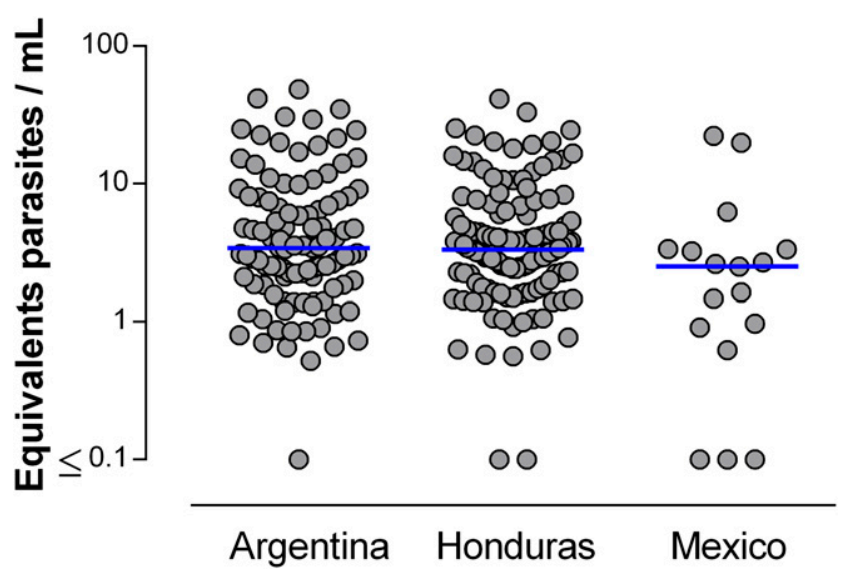

FIGURE 2. Parasitic load (equivalent parasites $/ \mathrm{mL}$ ) measured by real-time polymerase chain reaction (PCR) in maternal blood from seropositive mothers (with at least one positive antibody rapid test in cord blood and a positive enzyme-linked immunosorbent assay Wiener in maternal blood) by country, with medians. This figure appears in color at www.ajtmh.org.

parasitic load in Argentine mothers of congenital cases than in nontransmitting $T$. cruzi seropositive women (median parasitic load: $7.5 \mathrm{eP} / \mathrm{mL}$ versus $3.1 \mathrm{eP} / \mathrm{mL} ; P=0.088$ ), whereas parasitic loads were similar in Mexican mothers (median parasitic load: $2.1 \mathrm{eP} / \mathrm{mL}$ versus $2.5 \mathrm{eP} / \mathrm{mL} ; P=1.00)$.

In Argentina, three of the nine congenital cases had a premature rupture of the membranes (PROM), and among them one was born preterm ( $<37$ weeks) and admitted to a special care unit. In one case with PROM delivered at 37 weeks of gestation, the newborn was hospitalized in an intensive care unit at 15 hours of life for multiple symptoms including hepatomegaly, jaundice, and sepsis and was discharged alive after
17 days. The Mexican case identified at birth had an Apgar below 7 at 1 minute, and the other Mexican case had no complications.

We found 12 infected siblings in Argentina, three in Honduras, and none in Mexico (Table 4). One sibling in Argentina was previously treated for $T$. cruzi infection. No sibling was previously treated for $T$. cruzi infection in Honduras. All nonpreviously treated siblings identified in Argentina were treated; all siblings in Honduras were referred to treatment.

\section{DISCUSSION}

To our knowledge, this is the first study using a common methodology to study congenital Chagas disease in three countries. We assembled a population-based sample by systematically recruiting women at delivery and by successfully following up more than $95 \%$ of them. All molecular analyses were performed in a single laboratory, and an independent data center monitored and analyzed the data and ensured that all laboratory analyses were blinded.

The $6.6 \%$ congenital transmission rate we observed in Argentina is similar to what was observed in previous studies. ${ }^{4}$ There was a trend for parasitic load in maternal blood to be higher among congenital cases than among the general population of $T$. cruzi seropositive women, as suggested by others. ${ }^{10,26,27}$ Using the same criteria as the ones used by Torrico et al., ${ }^{28} 33.3 \%$ (3/9) of cases from Argentina can be classified as "symptomatic newborns," which is similar to what the same authors observed in their more recent cohort from Bolivia. Torrico et al. also found a frequency of PROM of $36.7 \%$, again very similar to what we found in Argentina. We found and treated 12 infected siblings in Argentina, showing an additional benefit of identifying seropositive mothers.

TABLE 3

Parasitological examination and cord blood polymerase chain reaction (PCR) and Trypanosoma cruzi serology at 10 months in infants born from seropositive mothers (with at least one positive antibody rapid test in cord blood and a positive enzyme-linked immunosorbent assay [ELISA] Wiener in maternal blood) by country

\begin{tabular}{|c|c|c|c|c|c|c|}
\hline & \multicolumn{2}{|c|}{ Argentina $(N=136)$} & \multicolumn{2}{|c|}{ Honduras $(N=182)$} & \multicolumn{2}{|c|}{ Mexico $(N=32)$} \\
\hline & $n / N$ & $\%[\mathrm{Cl}]^{*}$ & $n / N$ & $\%[\mathrm{Cl}]^{*}$ & $n / N$ & $\%[\mathrm{Cl}]^{*}$ \\
\hline \multicolumn{7}{|l|}{ At birth } \\
\hline $\begin{array}{l}\text { Positive direct parasitological } \\
\text { examination }\end{array}$ & $2 \dagger \ddagger / 136$ & 1.5 & $4 \ddagger \S / 181$ & 2.2 & $2 \ddagger \S / 28$ & 7.1 \\
\hline $\begin{array}{l}\text { Positive cord blood PCR among infants } \\
\text { with positive parasitological } \\
\text { examination }\end{array}$ & $2 / 2$ & 100.0 & $0 / 4$ & 0.0 & $1 / 2$ & 50.0 \\
\hline \multicolumn{7}{|l|}{ At $4-8$ weeks } \\
\hline $\begin{array}{l}\text { Positive direct parasitological } \\
\text { examination }\end{array}$ & $1 \dagger \ddagger / 129$ & 0.8 & $0 / 175$ & 0.0 & $0 / 27$ & 0.0 \\
\hline \multicolumn{7}{|l|}{ At 10 months } \\
\hline Positive Stat-Pak & $8 / 114$ & 7.0 & $8 / 172$ & 4.7 & $2 / 28$ & 7.1 \\
\hline Positive T-Detect & $7 / 113$ & 6.2 & $3 / 172$ & 1.7 & $0 / 28$ & 0.0 \\
\hline Positive ELISA Wiener & $6 / 115$ & 5.2 & $0 / 172$ & 0.0 & $0 / 28$ & 0.0 \\
\hline Positive ELISA Hemagen\| & $6 / 8$ & 75.0 & $0 / 11$ & 0.0 & $1 / 1$ & 100.0 \\
\hline $\begin{array}{l}\text { At } 10 \text { months by at least two positive } \\
\text { serological tests }\end{array}$ & $6+/ 113$ & 5.3 & $0 / 172$ & 0.0 & $1 \S / 28$ & 3.6 \\
\hline Congenital transmission $₫ \#$ & $9 \dagger / 136$ & $6.6[3.1,12.2]$ & $0 / 182$ & $0.0[0.0,2.0]$ & $2 \S / 32$ & $6.3[0.8-20.8]$ \\
\hline
\end{tabular}


TABLE 4

Trypanosoma cruzi serology among siblings born from seropositive mothers (with at least one positive antibody rapid test in cord blood and a positive enzyme-linked immunosorbent assay (ELISA) Wiener in maternal blood) by country

\begin{tabular}{|c|c|c|c|c|c|c|}
\hline & \multicolumn{2}{|c|}{ Argentina $(N=246)$} & \multicolumn{2}{|c|}{ Honduras $(N=408)$} & \multicolumn{2}{|c|}{ Mexico $(N=53)$} \\
\hline & $n / N$ & $\%$ & $n / N$ & $\%$ & $n / N$ & $\%$ \\
\hline Tested during follow-up & $209 / 246$ & 85.0 & $362 / 408$ & 88.7 & $50 / 53$ & 94.3 \\
\hline Positive Stat-Pak & 21/207 & 10.1 & $17 / 362$ & 4.7 & $1 / 50$ & 2.0 \\
\hline Positive ELISA Wiener & $13 / 207$ & 6.3 & $3 / 354$ & 0.9 & $0 / 47$ & 0.0 \\
\hline Stat-Pak and ELISA Wiener both positive & $12 / 205$ & 5.9 & $3 / 354$ & 0.9 & $0 / 47$ & 0.0 \\
\hline Referred to treatment & $12 / 12$ & 100.0 & $3 / 3$ & 100.0 & - & - \\
\hline
\end{tabular}

The congenital transmission rates observed in Mexico were comparable to Argentina. The case of congenital infection detected at birth in Mexico was referred to treatment but has not been treated yet because of the limited access to treatment in that country. ${ }^{29}$ Interestingly, this infant was seronegative at 10 months, suggesting a possible self-cure, as proposed elsewhere. ${ }^{10}$ We discarded one cord blood parasitological examination which was classified as positive at first, but had negative PCR on cord blood, was not treated, and was seronegative at 10 months. We cannot exclude that the case identified at 10 months was vector-borne because Triatoma dimidiata is present around and inside houses in Yucatán. ${ }^{30}$ In a previous household survey in two Mayan villages, we found three children infected by $T$. cruzi, and one of them had a $T$. cruzi seropositive mother. ${ }^{31}$

We did not confirm any case of congenital transmission in Honduras. We had to discard the four parasitological examinations which were classified as positive at first because they were not filmed and were assessed as doubtful by the supervising teams. Moreover, they had a negative PCR on cord blood, were not treated, and were all seronegative at 10 months. The possibility of self-cure, as suggested for the Mexican case previously, seems less probable here since $\mathrm{PCR}$, which is more sensitive than microscopic examination, was negative in cord blood. Our results do not mean that congenital transmission of $T$. cruzi does not occur in Honduras.

Our results pinpoint shortcomings concerning the diagnosis of $T$. cruzi infection, congenital or not. Serological tests need to be improved. Our previous study in four countries showed that Stat-Pak sensitivity was $94.6 \%$, with the Wiener ELISA as the gold standard, but that the sensitivity was lower in Mexico (62.5\%) than in Argentina (85.3\%) and Honduras $(95.4 \%) .{ }^{32}$ We added a second antibody rapid test (TDetect) in our present study to increase the sensitivity of our initial screening on cord blood. Table 2 shows that in Mexico, $32.1 \%$ of positive cord blood antibody rapid tests were positive for T-Detect only. Another challenge is that discrepancies between $T$. cruzi ELISAs were previously reported in Mexico. ${ }^{33}$ We also found more discrepancies between serological tests in Mexico than in the other countries (Table 2). The lack of sensitivity of antibody rapid tests and ELISAs might have been a source of underestimation of cases at 10 months.

Our results also strongly highlight the urgent need to improve diagnostic tools to reliably detect congenital infections as soon as possible. Among nine Argentine cases, only three were detected by parasitological examination in cord blood or at 4-8 weeks, confirming previous reports showing that direct parasitological examination sensitivity is limited. ${ }^{34}$ We also found that the positive predictive value of direct parasitological examination was low in Honduras and Mexico, despite extensive training of the laboratory technicians and close supervision. A low positive predictive value is expected when the prevalence is low, ${ }^{35}$ and identifying live $T$. cruzi parasites when they have never been detected can be difficult. Parasitological examinations were performed within a maximum of 6 hours after collecting the samples, and a second observer was often not available. We recommend filming parasitological examinations with smartphones to document the findings and to allow an evaluation by a second observer, which we performed in Argentina.

PCR on cord blood was positive in $69.8 \%$ of the newborns in Honduras, $45.6 \%$ in Argentina, and $24.1 \%$ in Mexico, suggesting a highly sensitive PCR (see Supplemental Material). The sensitivity of the PCR might have been increased by high performance DNA extraction, the use of GelRed ${ }^{\mathrm{TM}}$ nucleic acid stain, and the classification as positive of very faint amplicon bands, which were more frequently found in cord blood than in maternal blood samples (results not shown). Detection of DNA fragments without live parasites is another potential cause of the high frequency of positive cord blood PCR. Mouse models of congenital transmission showed up to $62 \%$ positive PCR among noninfected pups born to infected mothers, suggesting that DNA fragments were detected rather than live parasites. ${ }^{23}$ Maternal plasma DNA has been shown to cross the placental barrier into the fetal circulation. ${ }^{36}$ An early study found only $3 \%$ positive PCR among noninfected infants from infected mothers in Argentina. ${ }^{37}$ A study in Bolivia found no positive cord blood PCR among 109 uninfected infants but found transient positive PCR in one 7-day sample from a noninfected infant. ${ }^{34} \mathrm{~A}$ more recent study of 487 infants of $T$. cruzi infected mothers in Bolivia found higher numbers of false positive and borderline qPCR results. ${ }^{38}$ Another recent study found $20.0 \%$ positive PCR on cord blood among $T$. cruzi seropositive mothers in Guanajuato, Mexico. ${ }^{7}$ In Argentina, PCR positive rates as high as $30.8 \%$ in Jujuy and $27.2 \%$ in Formosa have been recently reported. ${ }^{39} \mathrm{PCR}$ on cord blood is not universally accepted for diagnosing congenital Chagas disease at birth. ${ }^{3}$ We, therefore, only used cord blood PCR negative results to identify false positive direct parasitological examinations because of reading errors.

Our data confirmed the expected predominance of non-Tcl in Argentina but surprisingly indicated a very similar situation in the two other countries, contrary to earlier reports. ${ }^{14}$ The high frequency of non-Tcl DTUs in Honduras and Mexico is in agreement with the recent findings of a greater diversity than previously reported in the $T$. cruzi DTUs circulating in Mexico and the US. ${ }^{16,40-42}$ It confirms the high frequency of non-Tcl infections in Mexican patients determined by lineage-specific serology. ${ }^{43}$ Our genotyping by PCR was limited to discriminating between $\mathrm{Tcl}$ and non-Tcl because of the very short 
sequence length of the marker used, and differences among non-Tcl DTUs should be studied further. PCR on maternal blood was less often positive in Mexico than in the other countries (Table 2), but when the PCR was positive, maternal parasitic load was similar in the three countries. This is somewhat surprising, with vector control programs being at different stages in each country. In Argentina, the interruption of transmission by Triatoma infestans in the Province of Tucumán was certified in $2015 .^{44}$ Honduras eliminated Rhodnius prolixus but is still exposed to other triatomines. ${ }^{45}$ Chagas vector control programs are very limited in Mexico. ${ }^{46}$ Some have found that repeated vectors exposure increases parasitic load, ${ }^{47}$ but others have found the opposite. ${ }^{26}$ One limitation of our study is that we do not have information on the country of origin of the mothers, but census data show that less than $0.5 \%$ of women residing in our study areas were born abroad. ${ }^{48-50}$

We conclude that mothers are predominantly infected by non-Tcl T. cruzi parasites across participating hospitals and T. cruzi DTU distributions in Mexico and Central America need to be further investigated. Similar risks of congenital transmission exist in Mexico and Argentina.

Received June 28, 2017. Accepted for publication October 21, 2017. Published online December 4, 2017.

Note: Supplemental material, table, and figures appear at www.ajtmh. org.

Acknowledgments: We thank A. Meyer for her help in preparing the article. We thank G. Tomasso (Unidad de Investigación Clínica y Epidemiológica Montevideo [UNICEM], Montevideo, Uruguay) for her support to data management; Renato Valenzuela (Instituto de Enfermedades Infecciosas y Parasitología Antonio Vidal, Tegucigalpa, Honduras) for his support to study management; M. Lewis and M. Miles (London School of Hygiene and Tropical Medicine, United Kingdom) for providing $T$. cruzi epimastigotes of genotype I (strain X10/I) or VI (strain CL Brener); P. Deblandre, S. Ait Djebbara, and A. Zucchi (Laboratory of Parasitology, Faculty of Medicine, Université Libre de Bruxelles [ULB], Brussels, Belgium) and S. Jameson (Department of Tropical Medicine, Tulane University, New Orleans, LA) for their technical help; and Fonds Emile Defay and Foundation David \& Alice Van Buuren from ULB for their support.

Financial support: This work was supported by the National Institute of Allergy and Infectious Diseases (grant number R01AI083563) and the Eunice Kennedy Shriver National Institute of Child Health \& Human Development (grant number T32HD057780).

Authors' addresses: Pierre Buekens, Eric Dumonteil, Claudia Herrera, Elizabeth Howard, and Dawn M. Wesson, Tulane University School of Public Health and Tropical Medicine, New Orleans, LA, E-mails: pbuekens@tulane.edu, edumonte@tulane.edu, cherrera@tulane.edu, ehoward3@tulane.edu, and wesson@tulane.edu. María Luisa Cafferata and Alvaro Ciganda, Unidad de Investigación Clínica y Epidemiológica Montevideo (UNICEM), Montevideo, Uruguay, E-mails: marialuisa.cafferata@gmail.com and aciganda@unicem-web.org. Jackeline Alger and Jorge A. García, Instituto de Enfermedades Infecciosas y Parasitología Antonio Vidal, Tegucigalpa, Honduras, E-mails: jackelinealger@yahoo.es and jalgar62_84@yahoo.com.ar. Fernando Althabe, José M. Belizán, and Luz Gibbons, Instituto de Efectividad Clínica y Sanitaria (IECS), Buenos Aires, Argentina, E-mails: falthabe@iecs.org.ar, belizanj@iecs.org.ar, and Igibbons@ iecs.org.ar. Norma Bustamante and Benjamín López, Región Departamental de Salud, Barrio Abajo, Santa Bárbara, Honduras, E-mails: hebuno@yahoo.com and benjalot@gmail.com. Yves Carlier, Université Libre de Bruxelles (ULB), Brussels, Belgium, and Tulane University School of Public Health and Tropical Medicine, New Orleans, LA, E-mail: ycarlier@ulb.ac.be. Jaime H. del Cid, Centro de Salud Vicente Mejía Colindres, Barrio El Centro, Intibucá, Honduras, E-mail: jaimedelcid@gmail.com. Rubí Gamboa-León, Coordinación Académica
Región Huasteca Sur, Universidad Autónoma de San Luis Potosí, Tamazunchale, San Luis Potosí, México, E-mail: miriamrubi2012@gmail. com. Olga Graiff, Laura Susana Lara, and María Cecilia Robles, Instituto de Maternidad y Ginecología Nuestra Señora de las Mercedes, San Miguel de Tucumán, Argentina, E-mails: bichi96@yahoo.com.ar, laura_lara09@ yahoo.com.ar, and ceciro1203@hotmail.com. Jesús Gurubel Maldonado and María Jesús Ramírez-Sierra, Centro de Investigaciones Regionales "Dr. Hideyo Noguchi," Universidad Autónoma de Yucatán, Mérida, Mexico, E-mails: jesgurubel@gmail.com and rsierra@correo.uady. mx. María Luisa Matute and Christian Valladares, Laboratorio Nacional de Vigilancia de la Salud, Secretaría de Salud de Honduras, Tegucigalpa, Honduras, E-mails: marialuisamatuteg@yahoo.com.mx and christianvalladares22@yahoo.com. Sergio Sosa-Estani, Instituto Nacional de Parasitología "Dr. Mario Fatala Chaben," CONICET, ANLIS, Buenos Aires, Argentina, and Instituto de Efectividad Clinica y Sanitaria (IECS), Buenos Aires, Argentina, E-mail: ssosaestani@gmail. com. Carine Truyens, Laboratory of Parasitology, Faculty of Medicine, Université Libre de Bruxelles (ULB), Brussels, Belgium, E-mail: ctruyens@ ulb.ac.be. Concepción Zúniga, Instituto de Enfermedades Infecciosas y Parasitología Antonio Vidal, Hospital Escuela Universitario, Tegucigalpa, Honduras, E-mail: concepcionzuniga@gmail.com.

\section{REFERENCES}

1. World Health Organization, 2015. Chagas disease in Latin America: an epidemiological update based on 2010 estimates. Wkly Epidemiol Rec 90: 33-43.

2. Buekens $P$, Almendares $O$, Carlier $Y$, Dumonteil E, Eberhard $M$, Gamboa-Leon R, James M, Padilla N, Wesson D, Xiong X, 2008. Mother-to-child transmission of Chagas' disease in North America: why don't we do more? Matern Child Health $J$ 12: 283-286.

3. Carlier Y, Torrico F, Sosa-Estani S, Russomando G, Luquetti A, Freilij H, Albajar Vinas P, 2011. Congenital Chagas disease: recommendations for diagnosis, treatment and control of newborns, siblings and pregnant women. PLoS Negl Trop Dis 5: e1250.

4. Howard EJ, Xiong X, Carlier Y, Sosa-Estani S, Buekens P, 2014. Frequency of the congenital transmission of Trypanosoma cruzi: a systematic review and meta-analysis. BJOG 121: 22-33.

5. Guzman-Bracho C, Lahuerta S, Velasco-Castrejon O, 1998. Chagas disease. First congenital case report. Arch Med Res 29: 195-196.

6. Cardoso EJ et al., 2012. Maternal fetal transmission of Trypanosoma cruzi: a problem of public health little studied in Mexico. Exp Parasitol 131: 425-432.

7. Montes-Rincón LM, Galaviz-Silva L, González-Bravo FE, MolinaGarza ZJ, 2016. Trypanosoma cruzi seroprevalence in pregnant women and screening by PCR and microhaematocrit in newborns from Guanajuato, Mexico. Acta Trop 164: 100-106.

8. Olivera Mar A, Guillén Ortega F, Cruz Vidal S, Hernández-Becerril N, Pérez Galdamez E, Córdova Concepción G, Reyes PA, Monteón VM, 2006. Serological and parasitological screening of Trypanosoma cruzi infection in mothers and newborns living in two Chagasic areas of Mexico. Arch Med Res 37: 774-777.

9. Sasagawa E et al., 2015. Mother-to-child transmission of chagas disease in El Salvador. Am J Trop Med Hyg 93: 326-333.

10. Carlier Y, Truyens C, 2015. Congenital Chagas disease as an ecological model of interactions between Trypanosoma cruzi parasites, pregnant women, placenta and fetuses. Acta Trop 151: 103-115.

11. Virreira $\mathrm{M}$ et al., 2006. Congenital Chagas disease in Bolivia is not associated with DNA polymorphism of Trypanosoma cruzi. Am J Trop Med Hyg 75: 871-879.

12. Burgos JM et al., 2007. Direct molecular profiling of minicircle signatures and lineages of Trypanosoma cruzi bloodstream populations causing congenital Chagas disease. Int $J$ Parasitol 37: 1319-1327.

13. Luquetti $A O$, Tavares SB, Siriano La R, Oliveira RA, Campos DE, de Morais CA, de Oliveira EC, 2015. Congenital transmission of Trypanosoma cruzi in central Brazil. A study of 1,211 individuals born to infected mothers. Mem Inst Oswaldo Cruz 110: 369-376. 
14. Zingales B et al. 2012. The revised Trypanosoma cruzi subspecific nomenclature: rationale, epidemiological relevance and research applications. Infect Genet Evol 12: 240-253.

15. Brenière SF, Waleckx E, Barnabé $C, 2016$. Over six thousand Trypanosoma cruzi strains classified into discrete typing units (DTUs): attempt at an inventory. PLoS Negl Trop Dis 10: e0004792.

16. Ramos-Ligonio A, Torres-Montero J, López-Monteon A, Dumonteil E, 2012. Extensive diversity of Trypanosoma cruzi discrete typing units circulating in Triatoma dimidiata from central Veracruz, Mexico. Infect Genet Evol 12: 1341-1343.

17. Carlier Y, Sosa-Estani S, Luquetti AO, Buekens P, 2015. Congenital Chagas disease: an update. Mem Inst Oswaldo Cruz 110: 363-368.

18. Gebrekristos HT, Buekens $P, 2014$. Mother-to-child transmission of Trypanosoma cruzi. J Pediatr Infect Dis 3 (Suppl 1): S36-S40.

19. UNICEF, 2017. Global Databases: Institutional Deliveries. UNICEF. Available at: https://data.unicef.org/topic/maternal-health/ delivery-care/. Accessed March 31, 2017.

20. Buekens $P$ et al. 2013. Congenital transmission of Trypanosoma cruzi in Argentina, Honduras, and Mexico: study protocol. Reprod Health 10: 55.

21. Torrico MC, Solano M, Guzmán JM, Parrado R, Suarez E, AlonzoVega C, Truyens C, Carlier Y, Torrico F, 2005. Estimation of the parasitemia in Trypanosoma cruzi human infection: high parasitemias are associated with severe and fatal congenital Chagas disease. Rev Soc Bras Med Trop 38 (Suppl 2): 58-61.

22. Virreira M, Torrico F, Truyens C, Alonso-Vega C, Solano M, Carlier $\mathrm{Y}$, Svoboda M, 2003. Comparison of polymerase chain reaction methods for reliable and easy detection of congenital Trypanosoma cruzi infection. Am J Trop Med Hyg 68: 574-582.

23. Cencig S, Coltel N, Truyens C, Carlier Y, 2013. Fertility, gestation outcome and parasite congenital transmissibility in mice infected with Tcl, Tcll and TcVl genotypes of Trypanosoma cruzi. PLoS Negl Trop Dis 7: e2271.

24. BLAST, 2015. Basic Local Alignment Search Tool. Available at: http://blast.ncbi.nlm.nih.gov/Blast.cgi. Accessed November 9, 2016.

25. Tamura K, Peterson D, Peterson N, Stecher G, Nei M, Kumar S, 2011. MEGA5: molecular evolutionary genetics analysis using maximum likelihood, evolutionary distance, and maximum parsimony methods. Mol Biol Evol 28: 2731-2739.

26. Kaplinski $\mathrm{M}$ et al., 2015. Sustained domestic vector exposure is associated with increased Chagas cardiomyopathy risk but decreased parasitemia and congenital transmission risk among young women in Bolivia. Clin Infect Dis 61: 918-926.

27. Bua J, Volta BJ, Velazquez EB, Ruiz AM, Rissio AM, Cardoni RL, 2012. Vertical transmission of Trypanosoma cruzi infection: quantification of parasite burden in mothers and their children by parasite DNA amplification. Trans $R$ Soc Trop Med Hyg 106: 623-628.

28. Torrico F, Alonso-Vega C, Suarez E, Rodriguez $\mathrm{P}$, Torrico $\mathrm{M}$, Dramaix M, Truyens C, Carlier Y, 2004. Maternal Trypanosoma cruzi infection, pregnancy outcome, morbidity, and mortality of congenitally infected and non-infected newborns in Bolivia. Am J Trop Med Hyg 70: 201-209.

29. Manne JM, Snively CS, Ramsey JM, Salgado MO, Bärnighausen T, Reich MR, 2013. Barriers to treatment access for Chagas disease in Mexico. PLoS Negl Trop Dis 7: e2488.

30. Dumonteil E, Nouvellet P, Rosecrans K, Ramirez-Sierra MJ, Gamboa-León R, Cruz-Chan V, Rosado-Vallado M, Gourbière $S, 2013$. Eco-bio-social determinants for house infestation by non-domiciliated Triatoma dimidiata in the Yucatan Peninsula, Mexico. PLoS Negl Trop Dis 7: e2466.

31. Gamboa-León R, Ramirez-Gonzalez C, Pacheco-Tucuch FS, O'Shea M, Rosecrans K, Pippitt J, Dumonteil E, Buekens P, 2014. Seroprevalence of Trypanosoma cruzi among mothers and children in rural Mayan communities and associated reproductive outcomes. Am J Trop Med Hyg 91: 348-353.

32. Sosa-Estani $S$ et al., 2008. Use of a rapid-test on umbilical cord blood to screen for Trypanosoma cruzi infection in pregnant women in Argentina, Bolivia, Honduras, and México. Am J Trop Med Hyg 79: 755-759.

33. Guzmán-Gómez D, López-Monteon A, de la Soledad LagunesCastro M, Álvarez-Martínez C, Hernández-Lutzon MJ, Dumonteil E, Ramos-Ligonio A, 2015. Highly discordant serology against Trypanosoma cruzi in central Veracruz, Mexico: role of the antigen used for diagnostic. Parasit Vectors 8: 466.

34. Bern C et al., 2009. Congenital Trypanosoma cruzi transmission in Santa Cruz, Bolivia. Clin Infect Dis 49: 1667-1674.

35. Buekens P, Kaminski M, 1988. Epidemiological evaluation of prenatal screening procedures. Eur J Obstet Gynecol Reprod Biol 28 (Suppl): 53-67.

36. Lo YM, Lau TK, Chan LY, Leung TN, Chang AM, 2000. Quantitative analysis of the bidirectional fetomaternal transfer of nucleated cells and plasma DNA. Clin Chem 46: 1301-1309.

37. Schijman AG, Altcheh J, Burgos JM, Biancardi M, Bisio M, Levin $\mathrm{MJ}$, Freilij $\mathrm{H}, 2003$. Aetiological treatment of congenital Chagas' disease diagnosed and monitored by the polymerase chain reaction. J Antimicrob Chemother 52: 441-449.

38. Messenger LA et al., 2017. Towards improving early diagnosis of congenital Chagas disease in an endemic setting. Clin Infect Dis 65: 268-275.

39. Velázquez EB, Rivero R, De Rissio AM, Malagrino N, Esteva MI, Riarte AR, Ruiz AM, 2014. Predictive role of polymerase chain reaction in the early diagnosis of congenital Trypanosoma cruzi infection. Acta Trop 137: 195-200.

40. Herrera CP, Licon MH, Nation CS, Jameson SB, Wesson DM, 2015. Genotype diversity of Trypanosoma cruzi in small rodents and Triatoma sanguisuga from a rural area in New Orleans, Louisiana. Parasit Vectors 8: 123.

41. Ibanez-Cervantes G, Martinez-Ibarra A, Nogueda-Torres B, LopezOrduna E, Alonso AL, Perea C, Maldonado T, Hernandez JM, Leon-Avila G, 2013. Identification by Q-PCR of Trypanosoma cruzi lineage and determination of blood meal sources in triatomine gut samples in Mexico. Parasitol Int 62: 36-43.

42. Garcia MN, Burroughs H, Gorchakov R, Gunter SM, Dumonteil E, Murray KO, Herrera CP, 2017. Molecular identification and genotyping of Trypanosoma cruzi DNA in autochthonous Chagas disease patients from Texas, USA. Infect Genet Evol 49: 151-156.

43. Risso MG et al., 2011. Immunological identification of Trypanosoma cruzi lineages in human infection along the endemic area. Am J Trop Med Hyg 84: 78-84.

44. Dirección General de Programa Integrado de Salud Provincia de Tucumán, 2015. Proceso de Certificación de la Interrupción de la Transmisión Vectorial y Transfusional del T. cruzi en la Provincia de Tucumán. Tucumán, Argentina.

45. Hashimoto K, Schofield CJ, 2012. Elimination of Rhodnius prolixus in Central America. Parasit Vectors 5: 45.

46. Carabarin-Lima A, González-Vázquez MC, Rodríguez-Morales O, Baylón-Pacheco L, Rosales-Encina JL, Reyes-López PA, ArceFonseca M, 2013. Chagas disease (American trypanosomiasis) in Mexico: an update. Acta Trop 127: 126-135.

47. Torrico F, Vega C, Suarez E, Tellez T, Brutus L, Rodriguez P, Torrico M, Schneider D, Truyens C, Carlier Y, 2006. Are maternal re-infections with Trypanosoma cruzi associated with higher morbidity and mortality of congenital Chagas disease? Trop Med Int Health 11: 628-635.

48. Instituto Nacional de Estadísticas y Censos, 2010. Censo Nacional de Población, Hogares y Viviendas 2010, República Argentina. Available at: http://www.indec.gov.ar/nivel4_default. asp?id_tema_1=2\&id_tema_2=41\&id_tema_3=135. Accessed August 25, 2017.

49. Instituto Nacional de Estadística, 2013. XVII Censo Nacional de Población y VI de Vivienda 2013, Honduras. Available at: http:// www.ine.gob.hn/index.php/component/content/article?id=81. Accessed August 25, 2017.

50. Instituto Nacional de Estadística y Geografía, 2010. Censo de Población y Vivienda 2010, Estados Unidos de México. Available at: http://www.beta.inegi.org.mx/contenidos/proyectos/ ccpv/2010/tabulados/Basico/04_02B_MUNICIPAL_31.pdf. Accessed August 26, 2017. 